\title{
Wind-induced vibration control of energy dissipation outrigger on a super high-rise building
}

\author{
Zheng Lu \& Xiangdong He \\ College of Civil Engineering, Tongji Universtiy, Shanghai, China
}

\begin{abstract}
KEYWORD: energy dissipation, super high-rise building, outrigger, viscous damper, wind resistance, comfort level

ABSTRACT: With the increasing height of buildings, the frame-central core tube-outrigger structure system is widely used in super-tall buildings. At the same time, it becomes more and more popular to employ multi-outriggers in taller and super high-rise buildings. However, because of the fact that the vibration period of these skyscrapers is close to that of the fluctuating wind, the acceleration of structure caused by wind generally exceeds the level of comfort regulated by the corresponding codes. Targeting on a super high-rise building with multi-outriggers, viscous dampers are installed between an outrigger at some height and the mega column, namely to adopt energy dissipation outrigger with viscous dampers, thus the overlarge wind-induced accelerations will be under control. Besides, the article will also focus on the effectiveness of the wind vibration control by viscous dampers installed in an outrigger at different levels.
\end{abstract}

\section{INTRODUCTION}

Super high-rise buildings have been more and more popular in recent decades and frame-core tube structures are widely employed in skyscrapers. However, under the horizontal loads, the overturning moment is mainly resisted by the core tube, which will cause large top displacement because of the flexural deformation of the core tube. Moreover, the large height to width ratio of the core tube makes the structure slender and will cause the deficiency of the bearing capacity as well as the lateral stiffness. Consequently, the frame-core-outrigger structure system is widely used in super highrise buildings (Tan et al. 2014). However, in this kind of structure, the force transferring path and the stiffness distribution are changed due to the huge stiffness of the stiff stories. Meanwhile, when suffering from earthquake, the structure mainly fails near the stiff stories, which are called the irregular layers (Zhou \& Li, 2014).

Enlightened by the idea from Smith (Jeremiah 2006; Smith \& Willford, 2007), two viscous dampers in parallel are installed vertically between the mega columns and the core tube to make the best use of the huge vertical differential deformation of them. Two viscous dampers in parallel are installed, link parts are mechanically hinged. This kind of innovative energy dissipation outrigger truss as is shown in Fig. 1 will be applied in this paper (Lu Zheng et al. 2015). In the figure, symbol 1 represents viscous dampers linked in parallel in the ends, symbol 2 is mega columns, symbol 3 is the core tube, symbol 4 is horizontal chord, symbol 5 represents vertical rod, and symbol 6 represents inclined rod. Node A shows the inconsistence between the columns and the tube. Node B shows the mechanically hinged connection.

However, a problem for structure with multiple outriggers comes out. As we know, fluid viscous dampers will work better when they are located at the places with larger different vertical deformation. So we should get the right outrigger at some level to install dampers for the maximum possible vibration absorbing. This paper mainly discusses the influence of vibration control under wind loads when dampers placed at different level of outriggers. Through a practical super high-rise building and on the basis of large commercial finite element software Etabs, this paper will analyze the effects of dampers located at different level of outriggers and propose some practical advice and guidance. 


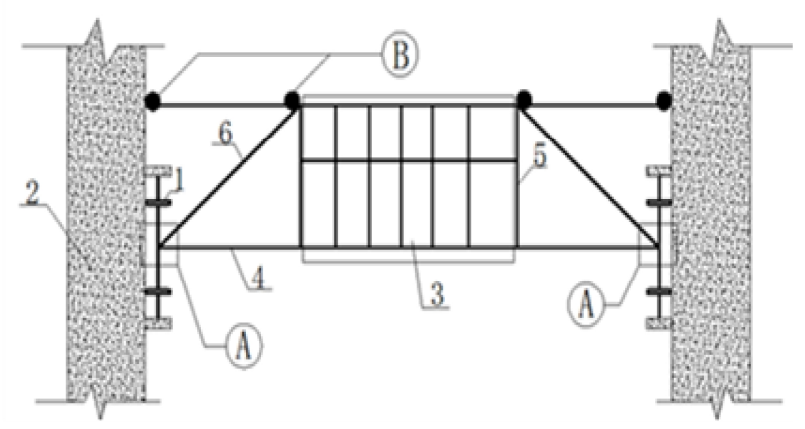

Fig.1 Configuration of the energy dissipation outrigger

\section{PROJECT OVERVIEW}

A super high-rise building, with the structure height of 598 meters and architecture height of 729 meters, has 137 floors overground and 5 floors underground. Meanwhile, the depth-width ratio is up to 8.7, which makes the structure an out-of-codes tall building. The main structure, whose lateral resisting system is core tube-column-outrigger, is frame-core-outrigger with five outriggers and we number the outriggers from top to bottom, 1 to 5 respectively. The plane layout of the structure is roughly a square, as is shown in Fig.2. The basic period of the super high-rise building is rather long and approximates to the period of fluctuating wind, which makes it sensitive to wind loads. This paper will mainly discuss the structure response control under wind loads.

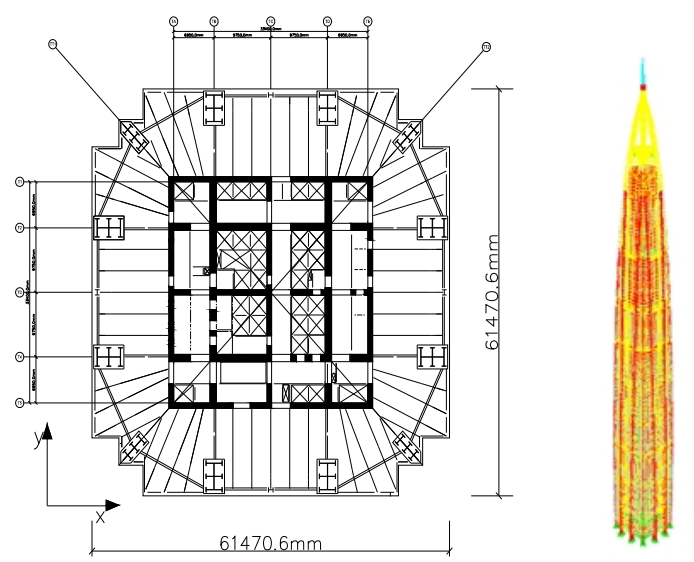
(a) Structure layout plan
(b) Etabs model

Fig.2 Structural plan layout and Etabs model of the structure

Analysis models are established through Etabs. The concrete strength grade of steel reinforced columns is C60 or C70 at different height and the steel strength grade of columns is Q345. On the other hand, the C60 concrete is used in the core and the strength grade of steel in steel beams is Q345. For the concrete composite floor, the strength grade of the concrete is C35. The load impacted on the structure is across-wind force in $\mathrm{X}$ direction with a 10 years return period. And the load time is 6050 seconds. This structure is located at area of 7 degree seismic fortification intensity and in earthquake group 1, the third site type, which are regulated in Chinese code for seismic design of buildings. All the wind load data come from experiment and the dead and live loads at floors are dependent on the function of the rooms.

\section{CACULATION MODELS AND DAMPING PARAMETERS}

To model the behavior of viscous damper, the Maxwell classical model is used. In this model, the damper element connects the spring in series, where the force formulation is $\mathrm{F}=\mathrm{C} v^{\alpha}$ and $\mathrm{F}$ stands 
for damper force, $\alpha$ stands for velocity exponent, $\mathrm{C}$ is the damper factor. Allowing for the huge height of the structure and the substantial persistent wind loads that the structure might suffer, excellent fluid viscous dampers are used in the analysis, where $x-0.2$ and $C=9000 \mathrm{KN} \cdot(s / \mathrm{m})^{n 2}$. As mentioned previously, two dampers are installed in parallel at each connection, the damper factor inputted in Etabs is $18000 \mathrm{KN} \cdot(\mathrm{s} / \mathrm{m})^{0.2}$. Also, to ensure the calculation efficiency, suggested by the Etabs Manual, let $\mathrm{K}=1000 \mathrm{C}$ and $\mathrm{K}$ is the stiffness of the spring.

Five different damping schemes are adopted in the paper to compare the work efficiency of the viscous dampers. In each scheme, only one outrigger connects to the perimeter column with dampers. We call them from scheme 1 at the top outrigger to scheme 5 at the bottom outrigger. The layout of dampers in the damping schemes is shown in Fig.3. Specifically, in scheme 1, the dampers are placed in the first outrigger located from story 119 to story 120 and only outrigger in north-south direction has dampers because of architectural reasons, namely, two dampers are placed at A, B, E, F, and there are 8 dampers in total in scheme 1 . In scheme 2 to 5 , the outriggers are located from story 103 to story 104 , story 88 to 90 , story 57 to story 59, story 25 to 27, respectively. And dampers are placed in both directions in these schemes. In total, there are two dampers at each place A to $\mathrm{F}$ and 16 dampers in total in each scheme.

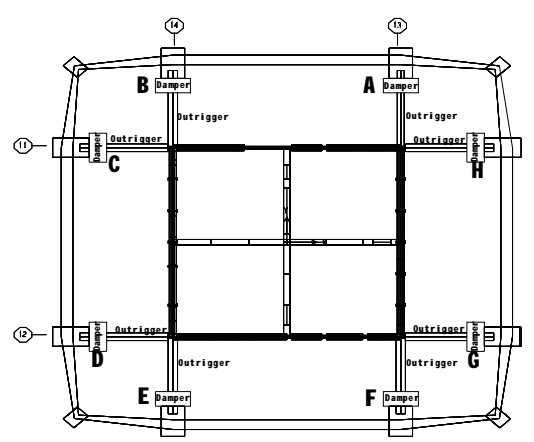

Fig3. The layout of dampers

As a control group, scheme 6 (also called conventional scheme or uncontrolled scheme) is without dampers, which means outriggers in this scheme are conventional and have no additional damping.

\section{CALCULATION RESULTS OF TEN-YEAR- RETURN PERIOD WIND LOADS}

\section{Wind load working condition}

The wind load from wind tunnel tests is a force time history with a 10 years return period (fluctuating wind, 6050s in total), and is loaded at the corresponding structure heights. The wind-induced acceleration is $0.306 \mathrm{~m} / \mathrm{s}^{2}$ at 598 meters high, namely the roof of the structure and the hotel (story137). In the roof of the apartment, where is 462.6 meters high and story 105 , the peak acceleration is $0.211 \mathrm{~m} / \mathrm{s}^{2}$. Consequently, the comfort level of the structure does not 
Tab.2 Vibration periods of the structure in different schemes (s)

\begin{tabular}{cccccccc}
\hline mode & Uncontrolled & $\begin{array}{c}\text { Scheme } \\
\text { one }\end{array}$ & $\begin{array}{c}\text { Scheme } \\
\text { two }\end{array}$ & $\begin{array}{c}\text { Scheme } \\
\text { three }\end{array}$ & $\begin{array}{c}\text { Scheme } \\
\text { four }\end{array}$ & $\begin{array}{c}\text { Scheme } \\
\text { five }\end{array}$ & $\begin{array}{c}\text { Mode di- } \\
\text { rection }\end{array}$ \\
\hline 1 & 9.19 & 9.20 & 9.28 & 9.37 & 9.41 & 9.35 & $\mathrm{X}$ \\
2 & 8.85 & 8.87 & 8.93 & 9.00 & 9.09 & 9.05 & $\mathrm{Y}$ \\
3 & 4.00 & 4.00 & 4.00 & 4.01 & 4.01 & 4.01 & $\mathrm{~T}$ \\
4 & 3.60 & 3.61 & 3.67 & 3.64 & 3.64 & 3.75 & $\mathrm{X}$ \\
5 & 3.36 & 3.40 & 3.42 & 3.40 & 3.42 & 3.53 & $\mathrm{Y}$ \\
6 & 2.04 & 2.04 & 2.04 & 2.04 & 2.04 & 2.04 & $\mathrm{~T}$ \\
\hline
\end{tabular}

Tab.3 Structural peak acceleration $\left(\mathrm{m} / \mathrm{s}^{2}\right)$ and the corresponding reduction effects

\begin{tabular}{ccccccc}
\hline Location & Uncontrolled & $\begin{array}{c}\text { Scheme } \\
\text { one }\end{array}$ & $\begin{array}{c}\text { Scheme } \\
\text { two }\end{array}$ & $\begin{array}{c}\text { Scheme } \\
\text { three }\end{array}$ & $\begin{array}{c}\text { Scheme } \\
\text { four }\end{array}$ & Scheme five \\
\hline $\begin{array}{c}\text { Roof of hotel } \\
\text { Vibration reduction } \\
\text { rate }\end{array}$ & 0.3056 & 0.2962 & 0.2469 & 0.2311 & 0.2286 & 0.2184 \\
$\begin{array}{c}\text { Roof of apartment } \\
\text { Vibration reduction }\end{array}$ & 0.2114 & 0.1971 & 0.1616 & 0.1589 & 0.1646 & 0.1555 \\
& & $6.08 \%$ & $19.21 \%$ & $24.38 \%$ & $25.20 \%$ & $28.53 \%$ \\
\hline
\end{tabular}

satisfy the corresponding requirements in Chinese code (JGJ61-2010 Technical specification for concrete structures of tall building $[\mathrm{J}]$ ). That is, under ten years return period wind load, the acceleration of hotel cannot exceed $0.25 \mathrm{~m} / \mathrm{s}^{2}$ and the counterpart for apartment is smaller than $0.15 \mathrm{~m} / \mathrm{s}^{2}$. Consequently, vibration control measures need to be taken.

\section{Structural periods}

Because of the fact that the connection parts between perimeter columns and outriggers are not rigid and are partly mechanically hinged, the periods of the structure will be influenced to some extent. The first six Periods of structure in each scheme are shown in Tab.2. As is shown in the Tab.2, differences between the damping schemes and uncontrolled scheme in periods are tiny. Schemes with lower outriggers damped have longer period in comparison with those damped at higher level. In general, structures with viscous dampers in outriggers will not change the fundamental periods of the original structure a lot, indicating the stiffness of the whole structure will not be influenced a lot.

\section{Inter-story drifts and story lateral displacement}

Inter-story drift and story lateral displacement are shown in Fig.4. Obviously, compared with conventional scheme, the inter-story drifts, especially at the upside, are well controlled in damping schemes. Scheme 3 has the smallest inter-story drifts, then followed by scheme 5, 4 and 2. Scheme 1 has the worst effect on drifts control for the architectural reason that there are only 8 dampers and its drifts approximate to the conventional scheme. As is required in current codes, for elastic design, under wind loads, the inter-story drifts of structures more than $250 \mathrm{~m}$ high should not exceed 1/500. From Fig.4 (a), it can be seen that the requirement is absolutely satisfied in all schemes. 


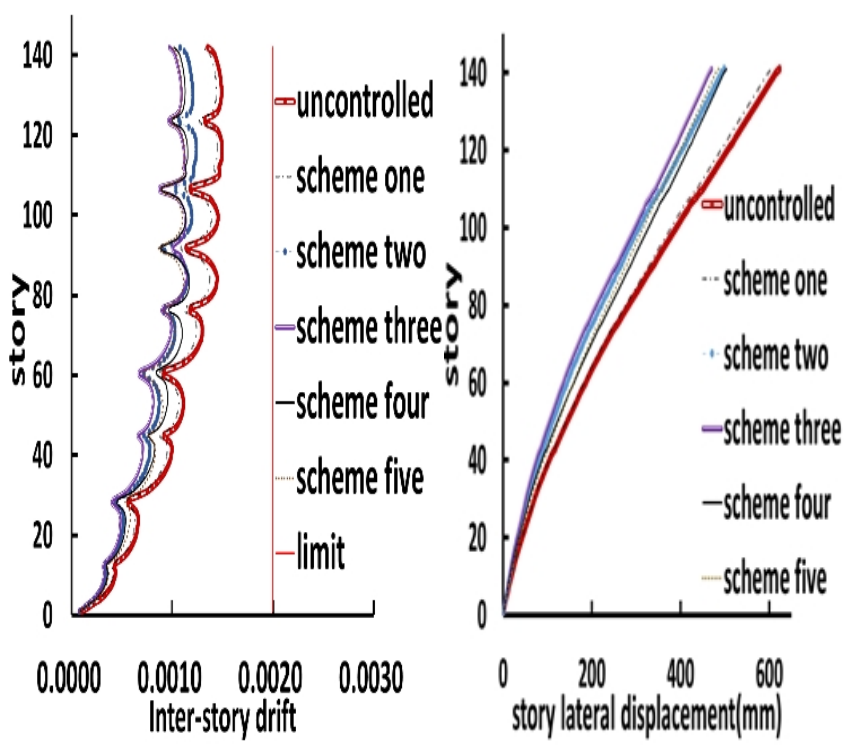
(a) Inter-story drifts
(b) story lateral displacements

Fig.4 Displacements response of stories under different outrigger schemes

From Fig.4 (b), the top displacements at conventional scheme and scheme 1 to 5 are $623 \mathrm{~mm}, 604$ $\mathrm{mm}, 498 \mathrm{~mm}, 470 \mathrm{~mm}, 503 \mathrm{~mm}$, and $485 \mathrm{~mm}$, respectively. It is easy to draw a conclusion that viscous damper can decrease the top displacements of the structure well. Scheme 3 has the smallest top displacement (24.6\% reduction), followed by scheme 5, 2, 4 and 1. However, except for scheme 1, all the damping schemes have tiny difference of only $33 \mathrm{~mm}$ (about 5\%) in top displacements. Thus, the height of placements of dampers impacts little on top peak lateral displacements.

\section{Acceleration damping effect}

As is shown in Tab.3, for the acceleration control, scheme 5 is the best, followed by scheme 4, 3, 2 and 1. The dampers at middle-lower part of the building have better control on floor acceleration than those at higher levels. This feature basically coincides with relative velocity of dampers, which is higher in scheme 5 and followed by scheme 4,3 and 2 .

Fig.5 is acceleration time histories at the top of the structure in scheme 4, 5 and the conventional scheme. As is shown in these curves, the viscous dampers can effectively decrease the acceleration of the structure and work well in reducing the vibration.

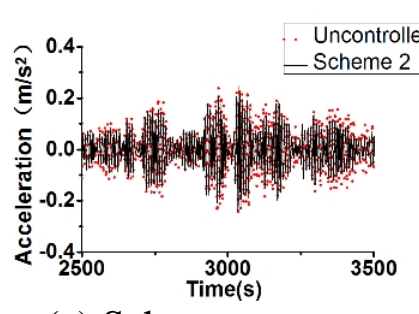

(a) Scheme two

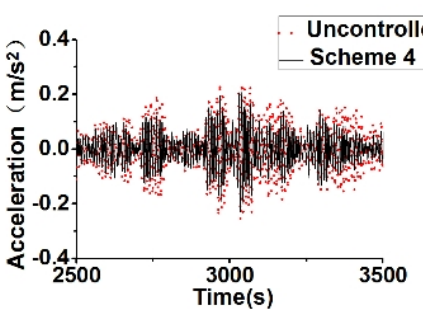

(c) Scheme four

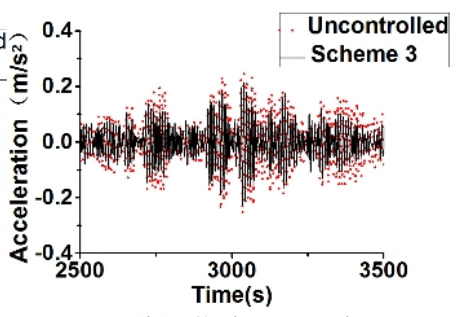

(b) Scheme three

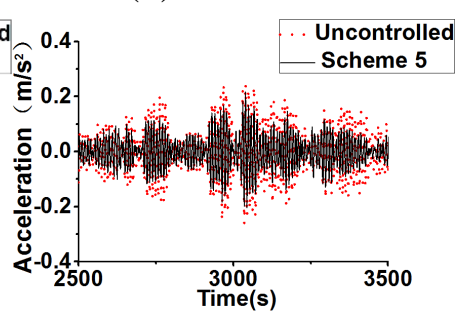

(d) Scheme five

Fig.5 Acceleration time histories at top floor 


\section{CONCLUSION AND PROSPECT}

This paper has proposed the problem of reasonable location of energy dissipation outriggers. In this kind of outriggers, viscous dampers are installed vertically to connect the outrigger with the perimeter column. This form of connection weakens the connection stiffness between mega columns and outriggers and therefore decreases the stiffness mutation in adjacent floors caused by the stiff stories. By comparing the conventional structure with damping structure, the responses of different schemes under 10 years return period wind load and the working performance of dampers have been analyzed. Several conclusions can be drawn from this article:

(1) Viscous dampers are velocity-dependent and will not largely affect the stiffness of the overall structure. In effect, vertically installing viscous dampers between outriggers and mega columns does enlarge the structure period, but this influence is rather small.

(2) Placing viscous dampers at the middle high outrigger (at 0.66 times of structure height) is the best choice for controlling the inter-story drifts and floor displacements. Meanwhile, all damping schemes have obvious smaller response than the conventional scheme.

(3) Based on the analysis of response of damping schemes, it is better to place viscous dampers at middle-lower outrigger than the upside counterpart.

\section{ACKNOWLEDGEMENTS}

Financial support from the National Natural Science Foundation of China through grant 51478361 is highly appreciated. The work is also supported by the Fundamental Research Funds for the Central Government Supported Universities.

\section{REFERENCES}

1) Jeremiah, Application of damping in high-rise building [D]. Massachusetts Institute of Technology, 2006.

2) Lu Zheng, He Xiangdong, Lu Xilin. Combined type energy dissipation and vibration reduction extending arm truss high-rise structure system. China practical new model patent CN204252270U. 2015.01.08

3) Professional Standard of the People's Republic of China. JGJ61-2010 Technical specification for concrete structures of tall building [J]. Beijing: China Architecture and Building Press, 2010 (in Chinese)

4) Smith RJ and Willford MR (2007), "The Damped Outrigger Concept for Tall Buildings," The Structural Design of Tall and Special Buildings, 16: 501-517.

5) Tan Ping, Fang Chuangjie and Zhou Fulin(2014), "Dynamic characteristics of a novel damped outrigger system," Earthquake engineering and vibration engineering, 13:293-304.

6)Zhou Ying and Li Hexian (2014), "Analysis of a high-rise steel structure with viscous damped outriggers," The Structural Design of Tall and Special Buildings, 23: 963-979 